\title{
Shingles (Herpes Zoster) Mimicking Acute Abdomen
}

\author{
Sherif Monib ${ }^{1}$, Emre Pakdemirli ${ }^{2}$
}

1. Breast Surgery, West Hertfordshire Hospitals NHS Trust, St. Albans and Watford General Hospitals, London, GBR 2. Radiology, West Hertfordshire Hospitals NHS Trust, St. Albans City Hospital, London, GBR

Corresponding author: Sherif Monib, sherif.monib@nhs.net

\section{Abstract}

Shingles is a very well-known viral infection caused by the varicella-zoster virus leading to painful skin rash. Although shingles can occur anywhere, it most often appears as a single stripe of blisters around the hypochondriac region. We are presenting a rare atypical presentation of shingles, as our patient presented with a picture of the acute abdomen a couple of days prior to the eruption of skin lesions.

Categories: Dermatology, Family/General Practice

Keywords: shingles, varicella zoster virus, shingles, herpes zoster, varicella zoster virus, acute abdomen, herpes zoster, abdominal rash, acute abdomen

\section{Introduction}

Varicella-zoster virus (VZV) is a member of the $\alpha$-herpesviruses subfamily and is a member of the Varicellovirus genus [1]. It can affect patients of any age, but primary VZV infection occurs during childhood leading to Varicella (chickenpox). Any reduction in the ability of an appropriate immune response could lead to reactivation of VZV from latency allowing the virus to travel anterogradely from the sensory ganglia to the skin nerve terminals and spreading to skin epithelial cells leading to the clinical signs of herpes zoster (HZ) [2].

It is usually a minor illness but can result in severe life-threatening complications in previously healthy patients. Herpes zoster rash usually involves a single dermatome and does not cross the midline. Thoracic, trigeminal, lumbar, and cervical dermatomes are the most frequent sites, but any area of the skin can be involved [3]. In rare cases, herpes zoster can present with atypical manifestations, like glioma, zoster sine herpete, and bilateral herpes zoster.

Review began 09/14/2020 Review ended 09/30/2020 Published 10/01/2020

\section{(c) Copyright 2020}

Monib et al. This is an open access article distributed under the terms of the Creative Commons Attribution License CC-BY 4.0., which permits unrestricted use, distribution, and reproduction in any medium, provided the original author and source are credited.

\section{Case Presentation}

We are presenting a case of a 53-year-old woman who was blue lighted from her workplace to the local accident and emergency department with severe, unbearable burning left upper quadrant pain radiating to the left lower thoracic region.

Her past medical history included indigestion and regurgitation under investigations, with no history of previous acute illness, similar conditions, or hospitalization. Her family history was irrelevant, the general examination was unremarkable, and her vital signs were within the normal range. Abdominal examination revealed a very tender, warm left hypochondrial region with hypersensitivity, with no organomegaly or visible skin lesions. Her ECG, as well as laboratory investigations including troponin level, were normal; her urine sample showed microscopic haematuria; a CT of the kidneys, ureters, and bladder (KUB) was carried out, which did not reveal any abnormality.

Due to the fact that she was hemodynamically stable and her biochemistry, as well as radiological investigations, were normal, she was discharged from the accident and emergency department with a provisional diagnosis of non-specific abdominal pain, with advice to see her general practitioner (GP) the following day for follow up as well as gastroenterology referral for investigation of indigestion and regurgitation.

Twenty-four hours later, she developed left hypochondrial/loin dry skin rashes (Figure 1); her GP provisional diagnosis was shingles based on her clinical picture. Subsequently, she was started on oral Solpadol ${ }^{\circledR}$ (paracetamol $500 \mathrm{mg}+$ codeine phosphate hemihydrate $30 \mathrm{mg}$ ) four times a day and oral acyclovir $800 \mathrm{mg}$ five times a day. She eventually fully recovered a week after without any complications; clinical examination six weeks after revealed a complete resolution of symptoms. 


\section{Cureus}

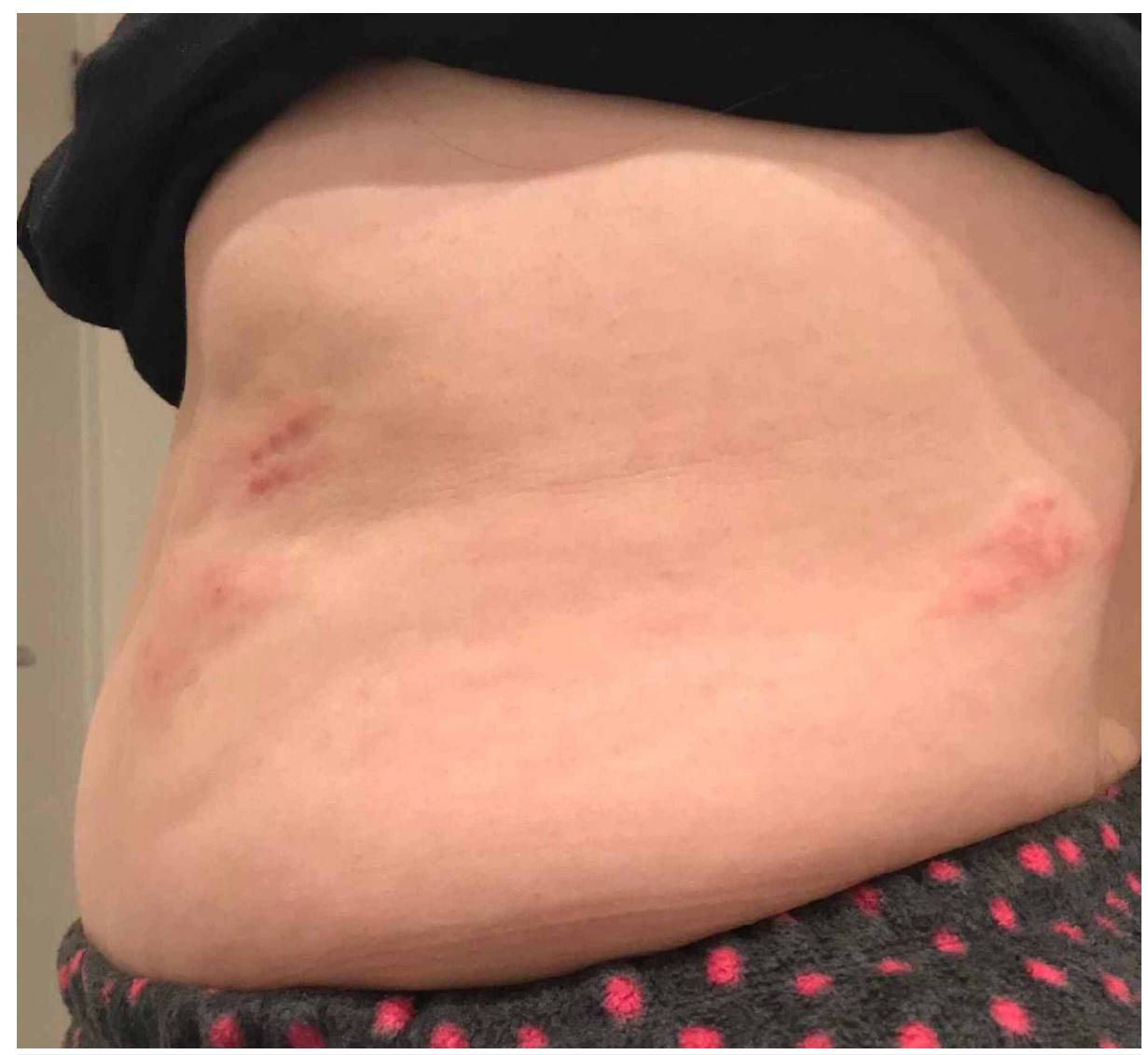

\section{FIGURE 1: Clinical photograph of the patient's abdomen}

Involved patchy areas noted in the patient's abdomen and loin.

\section{Discussion}

Varicella-zoster virus (VZV) was initially isolated in 1954 from the vesicular fluid of both chickenpox and zoster lesions in cell culture by Thomas Weller. In 1970 a live attenuated varicella vaccine was established in Japan [1].

VZV causes two clinically distinct diseases - a primary infection result in varicella (chickenpox), which is an extremely contagious acute infection that occurs mainly in school-aged children and is characterized by a generalized vesicular rash. Like other $\alpha$-herpesviruses, VZV establishes latency in neural tissue following primary infection. Reactivation of latent VZV from dorsal root ganglia leads to herpes zoster (shingles), which presents as localized cutaneous eruption associated by neuralgic pain that occurs most commonly in older patients. The typical clinical presentations of varicella and herpes zoster are easily recognized by most clinicians. In contrast, atypical clinical presentations and uncommon complications can be quite challenging not only to diagnose but also to treat [4].

The lifetime risk of herpes zoster is about $32 \%$. Increasing age and cellular immunosuppression are the most important risk factors - 50\% of persons living until age 85 years will develop it [4]. Herpes zoster infection is an interesting disease that involves many medical specialties including infectious diseases, dermatology, immunology, and neurology, while in most cases of $\mathrm{HZ}$ is a straight forward clinical diagnosis, an atypical presentation can be associated with a variety of severe and potentially lethal complications in both immunocompetent and immunocompromised persons. Therefore a low threshold of suspicion and early immunofluorescence assay for VZV antigen or polymerase chain reaction (PCR) assay, followed by adequate treatment involving different specialties as well as expertise in pain management and psychological support is required to reach a good outcome $[5,6]$.

Herpes zoster vaccine reduces the occurrence of the disease by about $50 \%$. The efficacy of the vaccine was found to be highest at 64\% in people aged 60-69, but unfortunately, its effectiveness declined with age - to $41 \%$ for people aged $70-79$, and $18 \%$ for those 80 years of age and older [7].

While most patients' symptoms settle down within a week with only simple analgesia, others might need antiviral medications like acyclovir, valacyclovir, famciclovir, and brivudine [8]. 


\section{Conclusions}

Atypical presentation of herpes zoster can lead to delay of diagnosis as well as the unfavorable outcomes. Herpes zoster infection should always be in mind when investigating patients presenting with acute onset of abdominal pain. We encourage reporting atypical cases of herpes zoster to create the opportunity to study different presentations and improve treatment modalities as well as outcomes.

\section{Additional Information \\ Disclosures}

Human subjects: Consent was obtained by all participants in this study. N/A issued approval N/A. This is a case report presentation and informed written consent was obtained. Conflicts of interest: In compliance with the ICMJE uniform disclosure form, all authors declare the following: Payment/services info: All authors have declared that no financial support was received from any organization for the submitted work. Financial relationships: All authors have declared that they have no financial relationships at present or within the previous three years with any organizations that might have an interest in the submitted work. Other relationships: All authors have declared that there are no other relationships or activities that could appear to have influenced the submitted work.

\section{References}

1. Wang L, Verschuuren EAM, van Leer-Buter CC, et al.: Herpes zoster and immunogenicity and safety of zoster vaccines in transplant patients: a narrative review of the literature. Front Immunol. 2018, 9:1632. 10.3389/fimmu.2018.01632

2. Sauerbrei A: Diagnosis, antiviral therapy, and prophylaxis of varicella-zoster virus infections . Eur J Clin Microbiol Infect Dis. 2016, 35:723-734. 10.1007/s10096-016-2605-0

3. Cohen KR, Salbu RL, Frank J, Israel I: Presentation and management of herpes zoster (shingles) in the geriatric population. P T. 2013, 38:217-227.

4. John WG: Varicella-zoster virus: atypical presentations and unusual complications . J Infect Dis. 2002, 186:S91-S98. 10.1086/342963

5. Dayan RR, Peleg R: Herpes zoster - typical and atypical presentations . Postgrad Med. 2017, 129:567-571. 10.1080/00325481.2017.1335574

6. Heaton PR, Espy MJ, Binnicker MJ: Evaluation of 2 multiplex real-time PCR assays for the detection of HSV$1 / 2$ and varicella zoster virus directly from clinical samples. Diagn Microbiol Infect Dis. 2015, 81:169-170. 10.1016/j.diagmicrobio.2014.11.012

7. U.S. Food and Drug Administration: Zostavax (herpes zoster vaccine) questions and answers. (2020). Accessed: 10 September 2020: https://www.fda.gov/vaccines-blood-biologics/vaccines/zostavax-herpeszoster-vaccine-questions-and-answers\#: : :text=Zo....

8. Gross GE, Eisert L, Doerr HW, et al.: S2k guidelines for the diagnosis and treatment of herpes zoster and postherpetic neuralgia. J Dtsch Dermatol Ges. 2020, 18:55-78. 10.1111/ddg.14013 